\title{
The Use of Transcatheter Laser Exposure in the Treatment of Cerebral Vessels Hypoplasia Accompanied by Migraine
}

\author{
Ivan V. Maksimovich \\ Clinic of Cardiovascular Diseases Named after Most Holy John Tobolsky, Moscow, Russia \\ Email: carvasc@yandex.ru
}

Received 24 July 2014; revised 12 September 2014; accepted 26 September 2014

Copyright (C) 2014 by author and Scientific Research Publishing Inc. This work is licensed under the Creative Commons Attribution International License (CC BY). http://creativecommons.org/licenses/by/4.0/

(c) (i) Open Access

\section{Abstract}

The research is dedicated to the possibility of restoring cerebral blood supply in patients with brain vessels hypoplasia accompanied by migraine. The research involved 67 patients aged 29 - 58 (average age 42) with severe migraine. The examination plan included laboratory diagnostics, assessment of dementia severity (CDR), assessment of cognitive impairment (MMSE), cerebral computed tomography (CT), cerebral magnetic resonance imaging (MRI), cerebral scintigraphy (SG), rheoencephalography (REG), cerebral multi-gated angiography (MUGA). Hypoplasia symptoms were detected in $56(83.58 \%)$ patients. To improve cerebral blood supply, the method of transcateter laser revascularization by means of low-energy CW lasers was used. Good immediate angiographic outcome manifested in persistent improvement of the intracranial vascular bed and marked collateral vascularization was obtained in $53(94.64 \%)$ patients. Good clinical outcomealmost complete regression of migraine and vestibular disorders-was obtained in $49(87.50 \%)$ patients. Satisfactory clinical outcome-partial regression of migraine and vestibular disorderswas observed in $7(12.50 \%)$ patients. The method of transcatheter laser revascularization of cerebral vessels is a physiological, effective and low-invasive treatment for patients suffering from cerebral vessels hypoplasia accompanied by migraine. This method has virtually no alternative; it stimulates natural angiogenesis causing collateral and capillary vascularization steadily improving the blood supply of the brain. The effect obtained after the treatment persists for a long time ( 9 years and longer), it causes regression of migraine, reduces mental disorders, and can improve the patients' quality of life.

\section{Keywords}

Headache, Migraine, Hypoplasia of Cerebral Vessels, Cerebrovascular Lesions, Angiogenesis, Transcatheter Laser Revascularization 


\section{Introduction}

The number of patients suffering from migraine has recently been growing. In the United States, the total number of patients complaining of debilitating headaches and migraines is about 30 million people [1]. According to different authors, the percentage of these patients varies considerably ranging from $0.5 \%$ to $2.2 \%$ of the whole population [2]. In spite of the disease expansion, patients do not always seek treatment, and in case they do, they do not always receive adequate assistance, the correct diagnosis being made in only $10 \%$ of cases [3].

The causes of migraine are not fully understood. However, the state of the vascular system of the brain plays an important role in the etiology and pathogenesis of the disease. Migraine is characterized, in almost $100 \%$ of cases, by hypoplasia of cerebral vessels, which is usually congenital and often hereditary in nature [4]. This lesion is characterized by a widespread, even narrowing of the lumen of intracranial arteries, the absence of atherosclerotic lesions and segmental stenosis, along with the absence of focal neurological deficit [4] [5].

The brain is the most highly perfused organ if compared to other human organs and tissues. It receives $750 \mathrm{ml}$ of blood a minute when at rest. Thus, an organ that is $2 \%$ of body weight receives almost $15 \%$ of the total minute blood volume. Besides, only the gray matter of the human brain alone consumes $20 \%$ of all oxygen consumed by the whole body [6]. The blood supply to the cerebral cortex and some parts of the gray matter is 300 $400 \mathrm{ml}$ per minute per 100 grams of the matter. The blood supply to the white matter of the brain is somewhat less being only $20 \%$ - $25 \%$ of the blood supply of the gray matter. Large arteries do not enter deep into the tissue, so the blood flow is carried out by small, reaching deep into the tissues arteries, the number of which is $12-27$ per cubic centimeter of the brain matter; at the same time, almost complete absence of arteriovenous shunts is normally observed [4] [6]-[8].

Thus, the brain is the main organ to be blood supplied, and therefore its tissues are very sensitive to any decrease in the blood flow [7]. Reduction of the inner diameter of the trunk of the anterior cerebral artery below $0.9 \mathrm{~mm}$ and of the trunk of the middle cerebral artery below $2.4 \mathrm{~mm}$ [8] indicates the presence of hypoplasia of the vessels.

The treatment of migraine is fairly complicated and not always efficient. In medical practice, a variety of ways is used to treat this disease [9]-[12]. However, it should be noted that practically none of these methods is aimed at affecting the vascular system of the brain and improving its blood supply, which determines the lack of efficacy of these methods. In the current situation, there remains a need to develop new methods of complex treatment of migraine, which would allow improving the blood supply in the brain.

This research is dedicated to interventional improvement of cerebral blood circulation in patients with cerebral vessels hypoplasia accompanied by severe migraine by means of transcatheter laser revascularization.

\section{Materials and Methods}

\subsection{Subject of Research}

The whole research and all transcatheter interventions have been carried out with the approval of the Ethics Committee, as well as with the consent of the examined and treated patients and their relatives.

We examined 67 patients aged 29 - 58 (average age 42) with severe migraine of whom 26 were male (38.81\%) and 41 (61.19\%) female.

The examination plan included laboratory diagnostics, assessment of the severity of dementia (CDR), assessment of cognitive impairment (MMSE), cerebral computed tomography (CT), cerebral magnetic resonance imaging (MRI), cerebral scintigraphy (SG), rheoencephalography (REG), cerebral multi-gated angiography (MUGA).

\subsection{Examination of Patients}

Laboratory examination was performed according to the schemes generally accepted in iterventional neuroangiology and included clinical, biochemical and coagulologic tests.

Assessment of the severity of dementia was made according to J.C. Morris's Clinical Dementia Rating scale (CDR) [13]. The first examination was conducted either during the patient's first visit or on the admission day, the second one-before the patient's discharge, and then at intervals of 6 - 12 months.

Assessment of cognitive impairment was conducted by means of Mini-Mental State Examination (MMSE) [14]. The first examination was conducted either during the patient's first visit or on the admission day, the 
second one-before the patient's discharge, and then at intervals of 6 - 12 months.

CT and MRI of the brain were performed on "Somatom" (Siemens), "Hi Speed" (GE), "Tomoscan” (Philips), "Apetro Eterna” (Hitachi) following the classical method. The first examination was conducted at the patient's admission and then at intervals of 6 - 12 months.

SG of the brain, with the determination of cerebral blood flow velocity, was carried out on a gamma camera (Ohio Nuclear, US) following the classical method in dynamic and static mode with TC 99M Pertechnetate 555. The first examination was conducted at the patient's admission and then at intervals of 6 - 12 months.

REG was conducted using "Reospektr-8" (Neurosoft, Russia) in accordance with the standard automated method with the identification of pulse blood flow in the cerebral hemispheres. The first examination was conducted at the patient's admission, the second one-before the patient's discharge, and then at intervals of 6 - 12 months.

MUGA of the brain was performed on apparatus "Advantx" (GE) following the classical method of transfemoral access. Synchronously, taking into account the start and rate of administration, $10-12 \mathrm{ml}$ of Omnipack 350 was introduced intra-carotidally and $7-8 \mathrm{ml}$ intra-vertebrally. The registration was carried out in direct and side projections in constant subtraction mode at a speed of 25 frames per second. Further, frame by frame analysis of the angiograms received in each phase contrast was conducted [15]. Capillary density contrast analysis was performed at the corresponding phase by means of an automatic method using computer program "Angio Vision” based on the determination of the degree of blackening of the corresponding part of brain tissue [16].

\subsection{Selection of Patients}

Criteria for the selection of patients for this research:

1) Consent of the patient and her/his relatives to conduct the examination and treatment;

2) Severe migraine refractory to or responding poorly to conservative treatment;

3) Absence of distinct atherosclerotic lesion of intracranial branches;

4) Hypoplasia of intracranial branches (the diameter of the trunk of the anterior cerebral artery of less than 0.9 $\mathrm{mm}$; the diameter of the trunk of the middle cerebral artery of less than $2.4 \mathrm{~mm}$ ) (Figures 1(A)-(C)).

For the transcatheter treatment, we selected 56 (83.58\%) patients aged 30 - 57 (average age 41), 21 male (37.50\%) and 35 female (62.50\%).

\subsection{Analysis of Patients}

- Signs of dementia equal to CDR-1 were detected in 4 (7.14\%) cases;

- Signs of cognitive impairment (MMSE score below 28 points) were detected in 6 (10.71\%) cases;

- Decreasing distinctiveness of gray and white matter borders-51 (91.07\%) cases;

- General involutive changes of the cerebral cortex accompanied by subarachnoid space extension were detected in 16 (28.57\%) cases;

- Indistinct surface of convexital surfaces of the hemispheres-15 (26,79\%) cases;
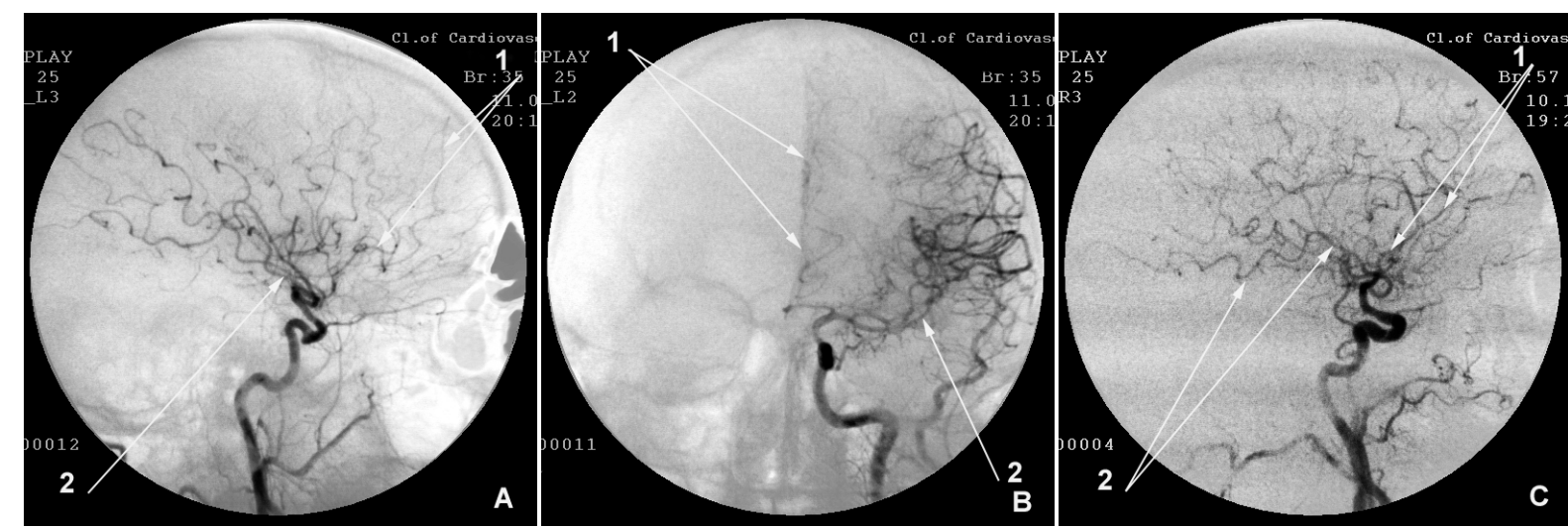

Figure 1. 1. The inner lumen of the anterior cerebral artery is significantly less than $0.9 \mathrm{~mm}$. 2 . The inner lumen of the middle cerebral artery is less than $2.4 \mathrm{~mm}$. 
- Expansion of Sylvian fissure was found in 14 (25.00\%) cases;

- Primary signs of unocclusive hydrocephalus were detected in 34 (60.71\%) cases;

- Slowing of linear velocity parameters of the blood flow in the cerebral hemispheres was observed in all 56 (100\%) cases;

- Decreased pulse volume blood flow in the carotid and vertebrobasilar systems was detected in all 56 (100\%) cases;

- No pronounced atherosclerotic lesion of intracranial branches was revealed in any case;

- Hemodynamically insignificant stenosis of extracranial arterial branches was detected in 9 (16.07\%) cases;

- Hypoplasia of intracranial branches was detected in all 56 (100\%) cases.

\subsection{The Method of Transluminal Laser Revascularization of Cerebral Vessels}

To conduct transcatheter laser exposure and stimulation of angiogenesis, we applied the method of transluminal laser revascularization [4] [15] [16] which allows to work on the vessels of a small diameter using low-energy laser systems. The efficacy and safety of this method is proved in earlier experimental and clinical studies [4] [17]-[21].

The essence of the method is the following:

Under local anesthesia, according to Seldinger's classical method, the common femoral artery is punctured and catheterized with an installation of an introducer with a $6 \mathrm{~F}$ diameter. Through this introducer and through coaxially brought guiding catheters installed in the general and further on in the internal carotid or in the vertebral artery, is brought a flexible fiber-optic instrument with a diameter of 25 - 100 micrometers, coupled with the laser unit. The fiber-optic instrument is first guided to the proximal and then to the distal sites of the anterior and middle cerebral arteries, where the laser treatment is carried out. The distal end of the fiber-optic instrument is constantly washed with heparinized saline solution. To carry out X-ray control, small doses of radiopaque substance are periodically introduced. The exposure time in general takes 20 - 40 minutes. The manipulation is carried out both in the right and in the left hemisphere. After the endovascular intervention the patient undergoes repeated cerebral multi-gated angiography following the procedure described above, the results of which determine the degree of revascularization and restoration of the cerebral vascular bed [15] [16]. We assume that if the cerebral blood flow has not been fully restored during the first attempt of the intervention, the manipulation can be repeated, but it was not necessary during the transcatheter interventions described.

The transcatheter treatment was followed by supportive therapy carried out by common interventional neuroangiology schemes and dosing. The patients underwent conventional desagrigant, anticoagulant, vasodilator and nootropic therapy including Aspirin, Heparin, indirect anticoagulants (depending on the blood coagulation indicators), Pentoxifylline $100 \mathrm{mg}$, Complamin $150 \mathrm{mg}$, Inosin $200 \mathrm{mg}$, Nootropil (Piracetam) $1200 \mathrm{mg}$ (or Gliatilin $1000 \mathrm{mg}$ ) intravenously, with a drop counter, №10-15, and then they took pills. Subsequent 1 2-months courses of pills were repeated twice a year.

\section{Results}

\subsection{Immediate Results}

A good immediate angiographic outcome manifested in the persistent recovery of the lumen and patency of the intracranial vascular bed and in collateral revascularization was obtained in 53 (94.64\%) cases.

\subsection{Results in the Early Period of 12 Months}

According to SG data, improved blood flow in the cerebral hemispheres was observed in 49 (87.50\%) cases, and the positive trend remained during practically the whole observation period (for 9 years and longer).

According to REG data, improved pulse-volume blood flow in the carotid and vertebrobasilar basins was found in all 55 (98.21\%) cases, and the positive trend also remained during practically the whole observation period.

According to CT and MRI data:

- Tendency to restore distinct boundaries between the gray and white matter of the brain was diagnosed in 48 (94.12\%) of 51 cases;

- General involutive changes in the cerebral cortex decreased in 15 (93.75\%) of 16 cases; 
- Tendency of the recovery of the covexital surface of the hemispheres was detected in 13 (86.66\%) cases out of 15 ;

- Reduction of Sylvian fissure narrowing was observed in 12 (85.71\%) of 14 cases;

- Reduction of unocclusive hydrocephalus signs was detected in 28 (82.75\%) of 34 cases.

\subsection{Clinical Results in the Short-Term Period}

Initial symptoms of dementia and cognitive impairment regressed in all patients.

- Good clinical outcome-almost complete regression of migraine and vestibular disorders, obtained in 49 (87.50\%) cases.

- Satisfactory clinical outcome-incomplete regression of migraine and vestibular disorders, observed in 7 (12.50\%) patients.

It should be noted that the obtained positive trend persisted and progressed in the more distant period after the treatment.

\subsection{Clinical Results in the Long-Term Period}

In the long-term period (2 - 9 years), 38 (67.87\%) patients were re-examined; the positive trend was maintained in the overwhelming number of patients treated:

- Good clinical outcome was initially obtained in 49 patients, of whom 34 were re-examined (69.39\%); the result was preserved in 32 (94.12\%);

- Satisfactory clinical outcome was initially obtained in 7 patients, of whom 4 were re-examined (57.14\%); the result was preserved in 3 (75.00\%).

\subsection{Complications}

During the laser treatment, there was no thrombosis or embolism in the distal arterial bed; as well as there was no deterioration of the patients' condition or progression of migraine.

\subsection{Treatment Examples}

Patient T., male, 40 years old, complaints: severe headaches resistant to conservative treatment, periodic vestibular disorders. Despite the fact that over the years the patient had been receiving medical treatment for migraine, the frequency and intensity of migraine attacks hardly decreased. The patient's condition is relatively satisfactory; there are no signs of dementia, MMSE-28 points.

CT of the brain revealed heterogeneity of the structure of the white matter, a moderate expansion of the subarachnoid space, signs of Sylvian fissure expansion (Figure 2).

SG and REG showed marked enough reduction in the blood flow and pulse blood volume, both the right and in the left hemisphere.

Cerebral MUGA revealed depletion of the vascular pattern, signs of hypoplasia of cerebral vessels (Figure 3).

The patient underwent transcatheter laser revascularization of the right and left hemispheres. Postoperative cerebral MUGA demonstrated no evidence of hypoplasia of cerebral vessels and marked collateral vascularization (Figure 4).

In the first days after the transcatheter intervention, the dynamics is positive, and headaches stopped. Repeated SG and REG showed positive dynamics of blood flow and pulse blood volume in both hemispheres of the brain. The patient was discharged in stable condition with no complaints, no signs of dementia or cognitive impairment and resumed his work connected with intellectual activity.

5 years after the transcatheter treatment, despite heavy amount of work and active intellectual activity, headaches do not disturb, there are no signs of dementia or cognitive impairment. SG and REG show that the indicators of blood flow and pulse blood volume are within the normal range. Repeated CT of the brain reveals recovery of the subarachnoid space, narrowing of Sylvian fissure, restoration of the structure of the cerebral tissue (Figure 5).

9 years after the transcatheter treatment, the patient still has no complaints, headaches do not disturb him, enjoys active intellectual activity, there is no cognitive impairment. SG and REG show that the indicators of blood flow and pulse blood volume are within the normal range. MRI of the brain demonstrates that the subarachnoid 
space is also within the normal range, there are no signs of involutive changes of the cerebral cortex (Figure 6). Cerebral MRA (Figure 7) does not reveal any signs of intracranial branches hypoplasia and shows preserved marked collateral vascularization.

\section{Discussion}

Migraine is caused by hypoplasia of the cerebral vessels, which reduces blood flow and long-term chronic hypoxia of the cerebral tissue [4] [5]. Due to the fact that this process is congenital, the blood supply of the brain constantly remains in the state of subcompensation, and it leads to the fact that patients become extremely sensitive to any external irritants. Consequently, any slightest impact may enhance the vascular tone, stimulate spastic effect and cause a migraine attack.

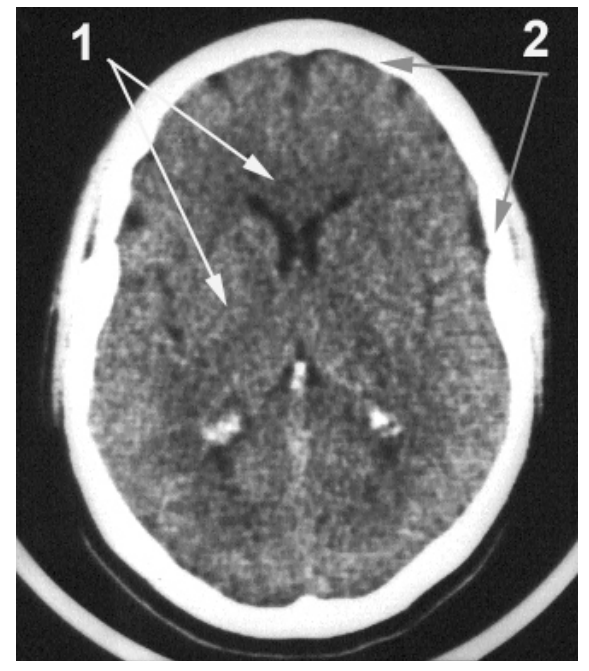

Figure 2. Patient T. male, 40 years old: CT of the brain. BEFORE THE OPERATION:

1. Uneven structure of the white matter; 2. Moderate expansion of subarachnoid space.

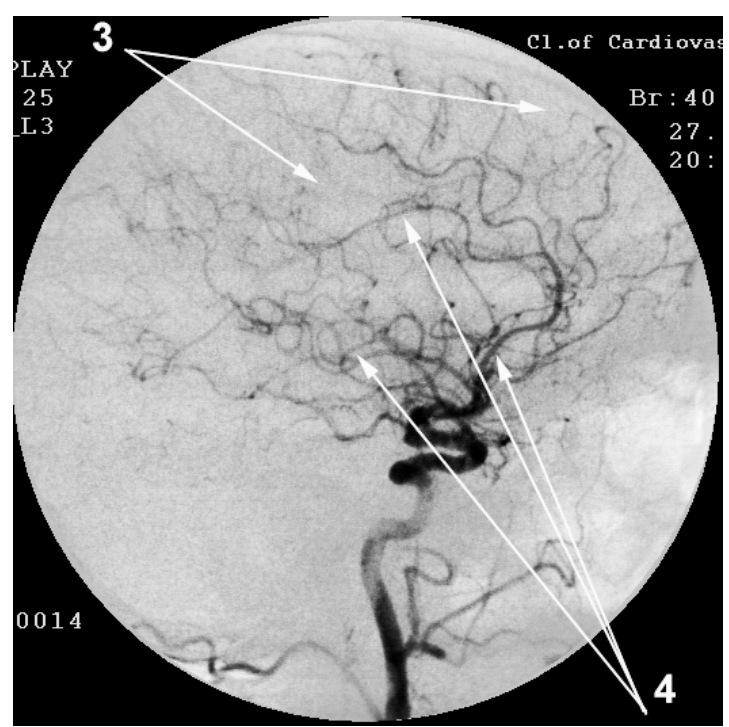

Figure 3. Same Patient T.: right-sided carotid MUGA (lateral projection). BEFORE THE OPERATION: 1. Vascular pattern depletion; 2. Signs of intracranial vessels hypoplasia. 


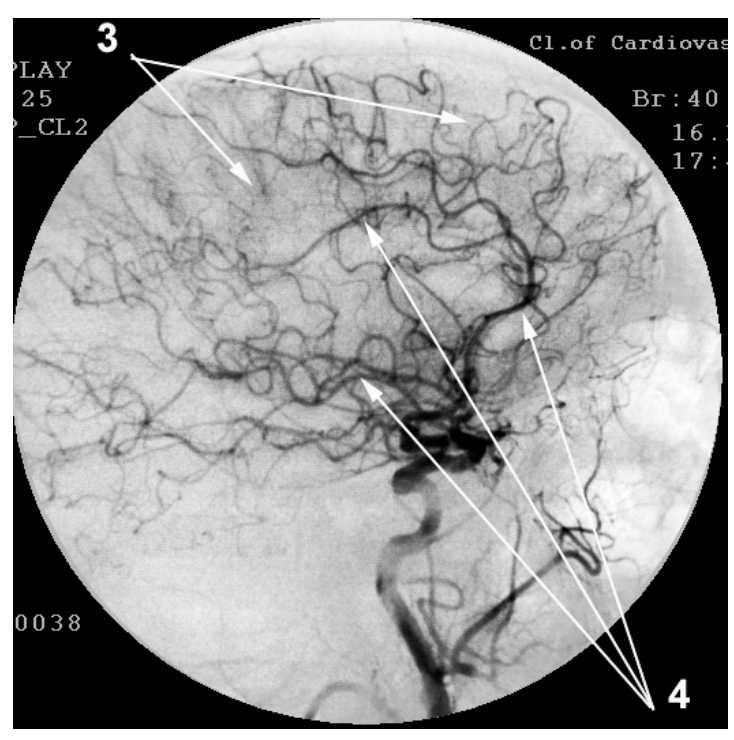

Figure 4. Same Patient T.: right-sided carotid MUGA (lateral projection). AFTER THE OPERATION: 1. Vascular pattern restoration, marked collateral vascularization; 2. No signs of vascular hypoplasia.

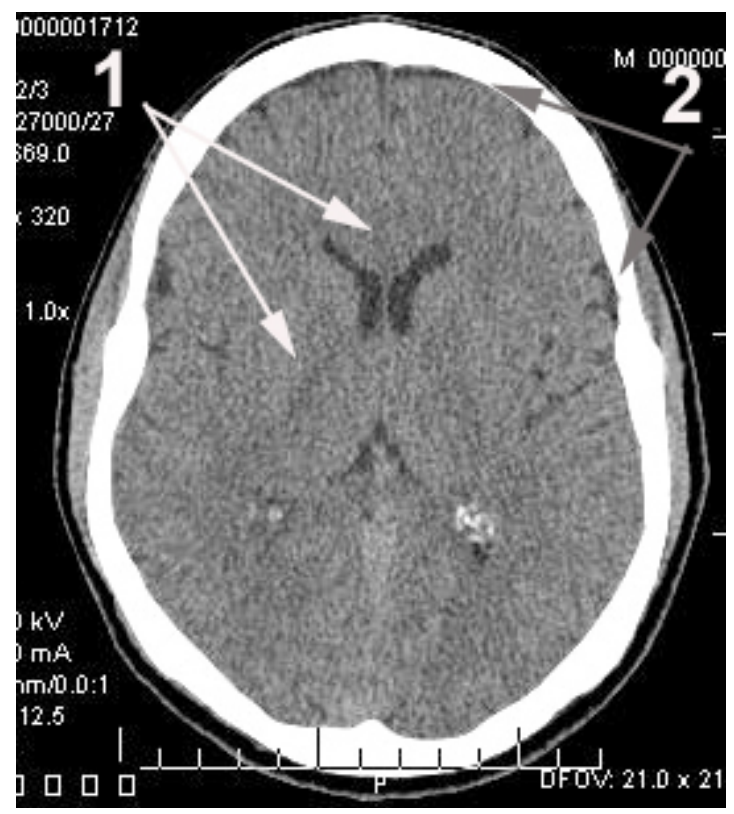

Figure 5. Same Patient T.: CT of the brain. 5 YEARS AFTER THE OPERATION: 1 . Subarachnoid space resto- ration; 2. Signs of cerebral tissue structure restoration.

Drug treatment of hypoplasia of cerebral vessels based on vasoactive drugs that act on the vascular wall is inefficient because the process is innate. It may seem plausible to use drugs that improve blood rheology, but this kind of therapy is usually inadequate [19] [20]. With cerebrovascular hypoplasia, conservative treatments fail to achieve pervasive and persistent cerebral vascularization. They only allow to improve the blood circulation to a certain degree and for a short time and thereby relieve a migraine attack. Reconstructive vascular intervention is not possible due to the fact that cerebral angiopathy is innate. As a result, the idea of using interventional therapies occurred. 


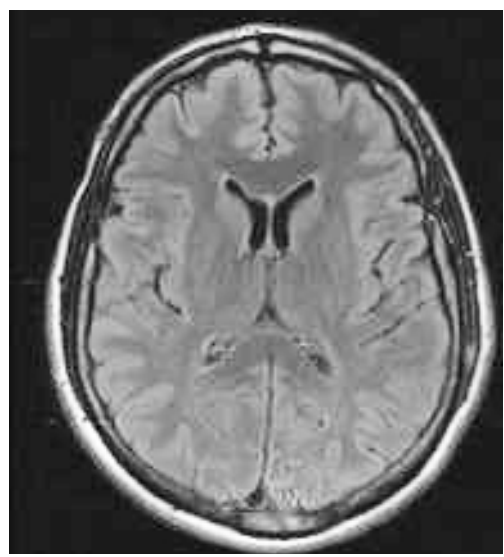

Figure 6. Same Patient T.: CT of the brain. 9 YEARS AFTER THE OPERATION: Subarachnoid space in the normal range, there are no structural disorders.

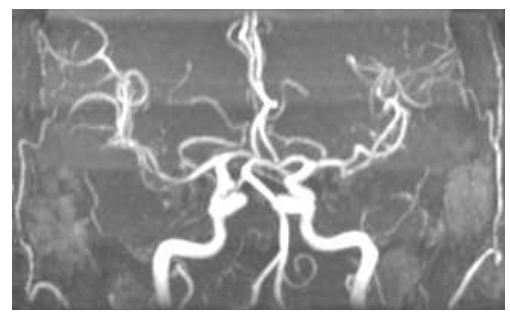

Figure 7. Same Patient T.: MRA of the brain. 9 YEARS AFTER THE OPERATION: No signs of cerebral vessels hypoplasia.

Considering the mechanism of low-energy laser exposure, it should be noted that it is essentially a powerful natural stimulation of physiological angiogenesis [4] [19] [20] causing anti-protective reaction, collateral and capillary vascularization of the tissues [15] [16]. Simultaneously, laser energy penetrates deeply enough into cerebral tissues and stimulates metabolic processes in neurons increasing the energy resource of the cells by acting on mitochondria, which leads to neuroprotective effects [17]. These data are supported by works of many authors who conducted experimental and clinical studies on extracranial laser action on the brain in various pathological conditions [22]-[27].

The method of transcatheter laser revascularization of cerebral vessels is a physiological, effective and lowinvasive treatment for patients suffering from cerebral vessels hypoplasia accompanied by migraine. This method has virtually no alternative; it stimulates natural angiogenesis causing collateral and capillary vascularization and thus steadily improves the blood supply of the brain, which, in its turn, prevents migraine attacks.

The effect obtained after the treatment persists for a long time (up to 9 years or more); it causes regression of migraine, reduces mental disorders, and can improve the patients' quality of life.

\section{References}

[1] Guyuron, B., Reed, D., Kriegler, J.S., Davis, J., Pashmini, N. and Amini, S. (2009) A Placebo-Controlled Surgical Trial of the Treatment of Migraine Headaches. Plastic and Reconstructive Surgery, 124, 461-468.

http://www.ncbi.nlm.nih.gov/pubmed/19644260 http://dx.doi.org/10.1097/PRS.0b013e3181adcf6a

[2] Bright, R., Bright, M., Bright, P., Hayne, S. and Thomas, W.D. (2014) Migraine and Tension-Type Headache Treated with Stromal Vascular Fraction: A Case Series. Journal of Medical Case Reports, 30, 237. http://www.ncbi.nlm.nih.gov/pubmed/24981130 
http://dx.doi.org/10.1186/1752-1947-8-237

[3] Paemeleire, K., Louis, P., Magis, D., Vandenheede, M., Versijpt, J., Vandersmissen, B. and Schoenen, J. (2014) Diagnosis, Pathophysiology and Management of Chronic Migraine: A Proposal of the Belgian Headache Society. Acta Neurologica Belgica. http://www.ncbi.nlm.nih.gov/pubmed/24968722

[4] Maksimovich, I.V. (2011) Transcatheter Laser Irradiation in the Treatment of Migraine. Journal of the American College of Cardiology, 58, 193-193. http://content.onlinejacc.org/article.aspx?articleid=1147653\&resultClick=3 http://dx.doi.org/10.1016/j.jacc.2011.10.740

[5] Alpaidze, M. and Beridze, M. (2014) Reversible Cerebral Vasoconstriction Syndrome and Migraine: Sonography Study. Georgian Medical News, 228, 28-36. http://www.ncbi.nlm.nih.gov/pubmed/24743119

[6] Folkow, B. and Neil, E. (1971) Circulation. Oxford University Press, London-Toronto. http://books.google.ru/books/about/\%E5\%BE\%AA\%E7\%92\%B0.html?id=KkQmNQEACAAJ\&redir_esc=y

[7] Gjulev N.M., Pustozertsev, V.G. and Gjulev, S.N. (2002) Cerebrovascular Diseases. BINOM, Moscow. http://www.combook.ru/product/158808/

[8] Luzha, D. (1973) X-Ray Anatomy of the Vascular System. Hungarian Academy of Sciences Publishing House, Budapest. http://рентгенхирургия.pф/?p=394

[9] Kelley, N.E. and Tepper, D.E. (2012) Rescue Therapy for Acute Migraine, Part 1: Triptans, Dihydroergotamine, and Magnesium. Headache, 52, 114-128. http://www.ncbi.nlm.nih.gov/pubmed/22211870 http://dx.doi.org/10.1111/j.1526-4610.2011.02062.x

[10] Kelley, N.E. and Tepper, D.E. (2012) Rescue Therapy for Acute Migraine, Part 2: Neuroleptics, Antihistamines, and Others. Headache, 52, 292-306. http://www.ncbi.nlm.nih.gov/pubmed/22309235 http://dx.doi.org/10.1111/j.1526-4610.2011.02070.x

[11] Kelley, N.E. and Tepper, D.E. (2012) Rescue Therapy for Acute Migraine, Part 3: Opioids, NSAIDs, Steroids, and Post-Discharge Medications. Headache, 52, 467-482. http://www.ncbi.nlm.nih.gov/pubmed/22404708 http://dx.doi.org/10.1111/j.1526-4610.2012.02097.x

[12] Orr, S.L., Aubé, M., Becker, W.J., Davenport, W.J., Dilli, E., Dodick, D., et al. (2014) Canadian Headache Society Systematic Review and Recommendations on the Treatment of Migraine Pain in Emergency Settings. Cephalalgia, Epub ahead of print. http://www.ncbi.nlm.nih.gov/pubmed/24875925 http://dx.doi.org/10.1177/0333102414535997

[13] Morris, J.C. (1993) The Clinical Dementia Rating (CDR): Current Version and Scoring Rules. Neurology, 43, 24122414. http://www.neurology.org/content/43/11/2412.2 http://dx.doi.org/10.1212/WNL.43.11.2412-a

[14] Folstein, M.F., Folstein, S.E. and McHugh, P.R. (1975) “Mini-Mental State”. A Practical Method for Grading the Cognitive State of Patients for the Clinician. Journal of Psychiatric Research, 12, 189-198. http://www.journalofpsychiatricresearch.com/article/0022-3956(75)90026-6/abstract http://dx.doi.org/10.1016/0022-3956(75)90026-6

[15] Maksimovich, I.V. (2006) Method for Carrying out Transluminal Laser-Induced Brain Revascularization in Atherosclerotic Injury Cases. RF Patent No. 2297861.

http://worldwide.espacenet.com/publicationDetails/biblio?II=3\&ND=3\&adjacent=true\&locale=en_EP\&FT=D\&date=2 0070427\&CC $=$ RU\&NR=2297861C1\&KC $=\mathrm{C} 1$

[16] Maksimovich, I.V. (2007) Method of Transluminal Laser Revascularization of Cerebral Blood Vessels Having Atherosclerotic Lesions. US Patent No. 7490612. http://www.lens.org/lens/patent/US_7490612_B2

[17] Maksimovich, I.V. (2004) Transljuminalnaja a Laser Angioplasty in Treatment of Ischemic Lesions of a Brain. M.D. Dissertation, Russian University of Friendship of the People, Moscow. http://disseng.com/page/order/id/206426.html

[18] Kuleshov, E.V. and Maksimovich, I.V. (1994) Endovascular Surgery in Patients over 65 with Disseminated Atherosclerosis of the Vessels of the Pelvis and Lower Extremities. Vestnik khirurgii imeni I. I. Grekova, 152, 27-30. http://www.ncbi.nlm.nih.gov/pubmed/7701734

[19] Maksimovich, I.V. (2012) Transcatheter Treatment of Atherosclerotic Lesions of the Brain Complicated by Vascular Dementia Development. World Journal of Neuroscience, 2, 200-209. http://www.scirp.org/journal/PaperInformation.aspx?PaperID=24664

[20] Maksimovich, I.V. (2013) Possibilities of Transcatheter Treatment of Patients after Extensive Ischemic Stroke. World Journal of Neuroscience, 3, 171-185. http://www.scirp.org/journal/PaperInformation.aspx?paperID=35031\&\#abstract

[21] Maksimovich, I.V. (2013) TCT-508 Transcatheter Treatment of Patients after Extensive Ischemic Stroke. Journal of the American College of Cardiology, 62, B155. http://content.onlinejacc.org/article.aspx?articleid=1759823

[22] Hashmi, J.T., Huang, Y.Y., Osmani, B.Z., Sharma, S.K., Naeser, M.A. and Hamblin, M.R. (2010) Role of Low-Level 
Laser Therapy in Neurorehabilitation. $P M \& R, 2$, S292-S305.

http://www.ncbi.nlm.nih.gov/pmc/articles/PMC3065857/

[23] Naeser, M.A. and Hamblin, M.R. (2011) Potential for Transcranial Laser or LED Therapy to Treat Stroke, Traumatic Brain Injury, and Neurodegenerative Disease. Photomedicine and Laser Surgery, 29, 443-446.

http://dx.doi.org/10.1089/pho.2011.9908

[24] Song, S., Zhou, F. and Chen, W.R. (2012) Low-Level Laser Therapy Regulates Microglial Function through Src-Mediated Signaling Pathways: Implications for Neurodegenerative Diseases. Journal of Neuroinflammation, 9, 219. http://www.ncbi.nlm.nih.gov/pubmed/22989325

[25] Konstantinović, L.M., Jelić, M.B., Jeremić, A., Stevanović, V.B., Milanović, S.D. and Filipović, S.R. (2013) Transcranial Application of Near-Infrared Low-Level Laser Can Modulate Cortical Excitability. Lasers in Surgery and Medicine, 45, 648-653. http://www.ncbi.nlm.nih.gov/pubmed/24136303 http://dx.doi.org/10.1002/lsm.22190

[26] Yang, X., Askarova, S., Sheng, W., Chen, J.K., Sun, A.Y., Sun, G.Y., Yao, G. and Lee, J.C.M. (2010) Low Energy Laser Light (632.8 nm) Suppresses Amyloid- $\beta$ Peptide-Induced Oxidative and Inflammatory Responses in Astrocytes. Neuroscience, 171, 859-868. http://www.sciencedirect.com/science/article/pii/S030645221001273X?np=y

[27] Barrett, D.W. and Gonzalez-Lima, F. (2013) Transcranial Infrared Laser Stimulation Produces Beneficial Cognitive and Emotional Effects in Humans. Neuroscience, 230, 13-23. http://www.ncbi.nlm.nih.gov/pubmed/23200785 http://dx.doi.org/10.1016/j.neuroscience.2012.11.016 
Scientific Research Publishing (SCIRP) is one of the largest Open Access journal publishers. It is currently publishing more than 200 open access, online, peer-reviewed journals covering a wide range of academic disciplines. SCIRP serves the worldwide academic communities and contributes to the progress and application of science with its publication.

Other selected journals from SCIRP are listed as below. Submit your manuscript to us via either submit@scirp.org or Online Submission Portal.
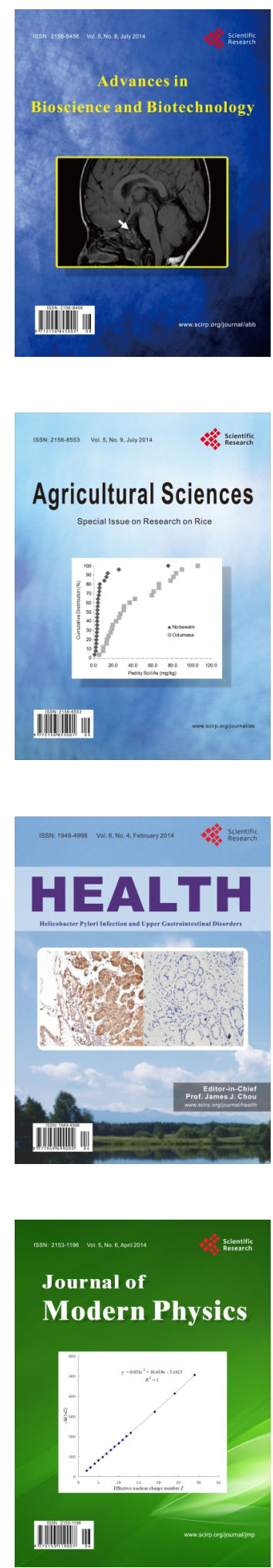
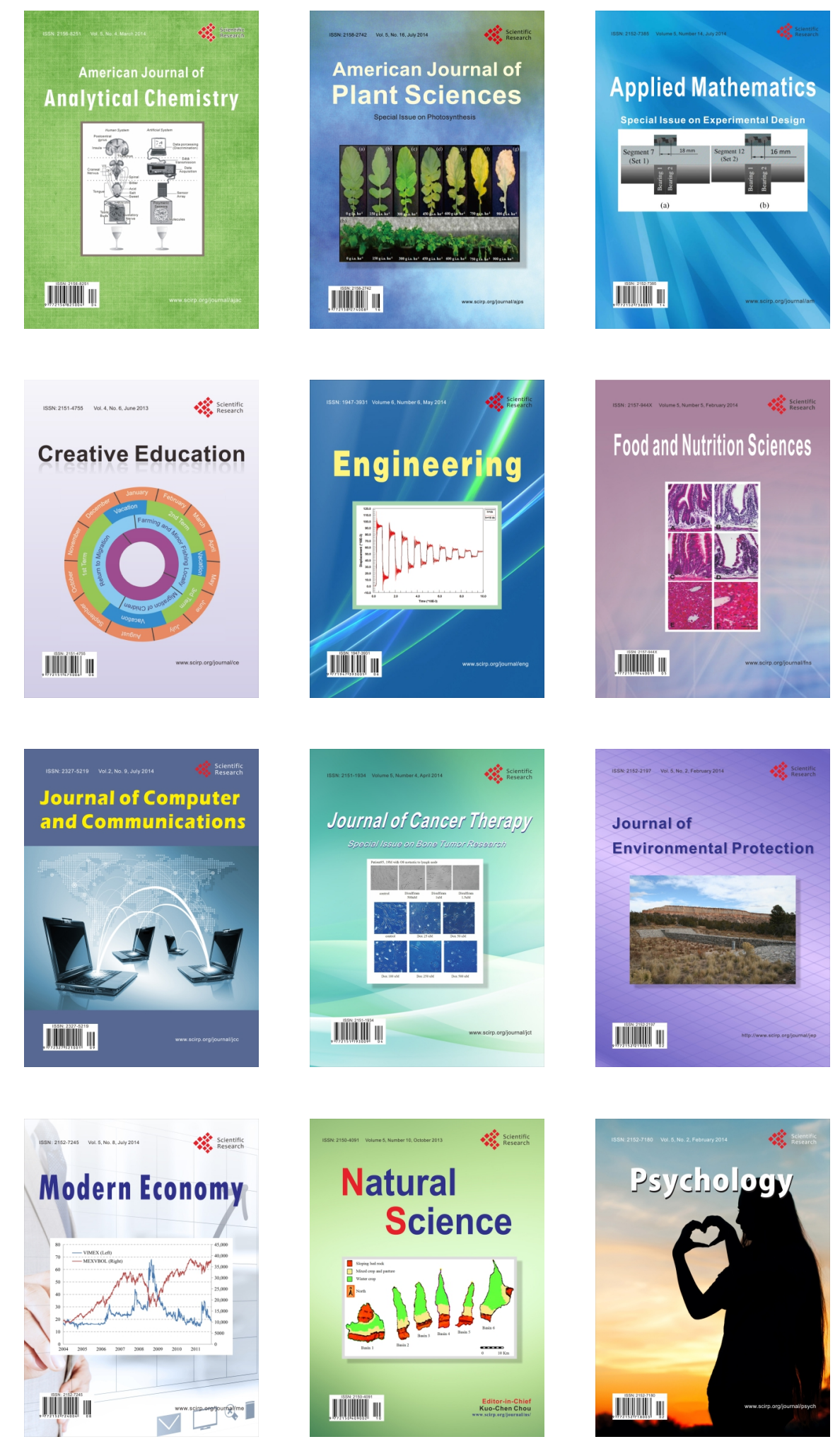